\title{
Depressive statements prime goal-directed alcohol-seeking in individuals who report drinking to cope with negative affect
}

\author{
Lee Hogarth ${ }^{1}$ (D) - Lorna Hardy ${ }^{1}$
}

Received: 14 June 2017 / Accepted: 13 October 2017 /Published online: 29 October 2017

(C) The Author(s) 2017. This article is an open access publication

\begin{abstract}
Background Most variants of negative reinforcement theory predict that acute depressed mood can promote alcoholseeking behaviour, but the precise mechanisms underpinning this effect remain contested. One possibility is that moodinduced alcohol-seeking is due to the formation of a stimulus-response (S-R) association, enabling depressed mood to elicit alcohol-seeking automatically. A second possibility is that depressed mood undergoes incentive learning, enabling it to enhance the expected value of alcohol and thus promote goal-directed alcohol-seeking.

Objectives These two explanations were distinguished using a human outcome-revaluation procedure.

Methods One hundred and twenty-eight alcohol drinkers completed questionnaires of alcohol use disorder, drinking to cope with negative affect and depression symptoms. Participants then learned that two responses earned alcohol and food points respectively (baseline) in two alternative forced choice trials. At test, participants rated the valence of randomly sampled negative and positive mood statements and, after each statement, chose between the alcohol- and food-seeking responses in extinction.

Results The percentage of alcohol- versus food-seeking responses was increased significantly in trials containing negative statements compared to baseline and positive statement trials, in individuals who reported drinking to cope with negative affect $(p=.004)$, but there was no such interaction with
\end{abstract}

Lee Hogarth

1.hogarth@exeter.ac.uk

1 School of Psychology, University of Exeter, Washington Singer Building, Perry Road, Exeter EX4 4QG, UK indices of alcohol use disorder ( $p=.87$ ) or depression symptoms $(p=.58)$.

Conclusions Individuals who drink to cope with negative affect are more sensitive to the motivational impact of acute depressed mood statements priming goal-directed alcoholseeking. Negative copers' vulnerability to alcohol dependence may be better explained by excessive affective incentive learning than by S-R habit formation.

Keywords Incentive learning · Goal-directed learning · Habit · Drug-seeking · Negative mood · Depression · Allostasis $\cdot$ Negative reinforcement $\cdot$ Alcohol

\section{Introduction}

The core tenet of negative reinforcement theory is that alcohol dependence is caused by withdrawal, emotional, or psychiatric states (such as agitation, depression, and anxiety) powerfully motivating alcohol use in order to mitigate these states (Baker et al. 2004; Cox and Klinger 1988; Eissenberg 2004; Hall et al. 2015; Kassel et al. 2003; Khantzian 1997; Koob and Volkow 2010; Marlatt 1996; Mathew et al. 2017; Sinha 2001; Solomon and Corbit 1973; Wikler 1984). However, the exact mechanisms by which adverse states trigger alcohol-seeking remain unclear. Several negative reinforcement accounts claim that negative affect triggers alcohol-seeking automatically, i.e. without forethought for the consequences (Baker et al. 2004; Everitt and Robbins 2016; Koob and Volkow 2010; Schwabe et al. 2011). This claimed automatic status of alcohol-seeking arguably explains why drinking persists despite significant harms or intentions to quit. These theoretical papers articulate two variants of the automatic account. According to one variant, alcohol's ability to mitigate adverse states means that alcohol is experienced as having a greater 
reward value in those states. The greater reward value of alcohol reinforces a strong direct association (connection) between the adverse state stimuli ( $\mathrm{S}$ ) and the alcohol-seeking motor response (R). These stimulus-response (S-R) links enable the adverse states to elicit the alcohol-seeking response automatically, unconsciously, habitually, or compulsively, i.e. without forethought for the wider harmful consequences of alcohol use or current intentions to quit. The second variant of the automatic account differs in that it presumes that adverse states (e.g. anxiety) acutely reduce cognitive capacity, favouring automatic control over alcohol-seeking by S-R links which have previously formed between external alcoholrelated stimuli and the alcohol-seeking response. By promoting automatic control over alcohol-seeking by external alcohol cues, adverse states reduce the influence of expected harms and intentions to quit on behaviour, and so promote dependence and relapse.

Other negative reinforcement theories, by contrast, claim that adverse affective states motivate alcohol-seeking by retrieving explicit coping motives - beliefs that alcohol can help mitigate adverse states (Cox and Klinger 1988; Kassel et al. 2003; Khantzian 1997; Marlatt 1996; Mathew et al. 2017; Sinha 2001). Such motivational negative reinforcement models may be specified in more mechanistic detail by being integrated with incentive learning theory (Dickinson and Balleine 2010; Hogarth et al. 2015; Hutcheson et al. 2001). According to this combined account, individuals who report drinking to cope with negative affective states are reporting their direct experience alcohol having a greater reward value because of its ability to acutely mitigate those states. This incentive learning experience enables negative affective states to raise the expected value of alcohol (in the same way that hunger raises the expected value of food, because food is more rewarding when hungry). The greater expected reward value of alcohol in the negative affective state is combined with instrumental knowledge of the responses that produce alcohol in the current environmental context (Hardy et al. 2017), thus promoting goal-directed (intentional) instrumental choice to obtain alcohol. In short, individuals who report drinking to cope with negative affect are vulnerable to alcohol dependence and relapse (Beseler et al. 2008; Crum et al. 2013a, b; Lazareck et al. 2012; Menary et al. 2011; Merrill et al. 2014; Robinson et al. 2011; Windle and Windle 2015), because negative affective states act as powerful motivators of goaldirected alcohol-seeking which overrule expected harms and intentions to quit (just as intense hunger might overrule weight loss intentions).

A key source of evidence supporting this particular incentive learning model is the finding that individuals who report drinking to cope with adverse affective states are more sensitive to the motivational impact of experimentally induced negative mood or stress on alcohol-seeking behaviour, as indexed by craving, consumption, preferential choice, or cognitive bias
(Austin and Smith 2008; Birch et al. 2004; Brady et al. 2006; Cooney et al. 1997; Field and Powell 2007; Field and Quigley 2009; Grant et al. 2007; Rousseau et al. 2011; Woud et al. 2015; Zack et al. 2003); but for null results, see (Field and Powell 2007; Thomas et al. 2014). The strong interpretation of these findings is that coping motives play a causal role in enabling mood induction to promote alcohol-seeking, rather than automatic S-R processes. However, because coping motives are only correlated with mood-induced alcohol-seeking, they could be merely epiphenomenal, while an S-R process is actually responsible for the effect. Existing studies cannot discriminate these two positions.

The outcome-revaluation procedure has provided a more decisive method for determining whether drug-seeking behaviour is controlled by incentive learning or S-R mechanisms, in both animals (Corbit et al. 2012; Dickinson et al. 2002; Hutcheson et al. 2001; Miles et al. 2003) and humans (Hogarth 2012; Hogarth and Chase 2011; Hogarth et al. 2013). The rationale of this method can be illustrated with one key study. Hutcheson et al. (2001) found that heroin withdrawal could augment a novel heroin-seeking response in an extinction test, but only in rats that had previously experienced heroin in the withdrawal state. This effect can be explained by incentive learning but not by S-R theory. Arguably, rats learn that heroin has greater reward value in the withdrawal state (incentive learning), enabling this state to raise the expected value of heroin, which integrates with instrumental knowledge of the novel heroin-seeking response, enabling goaldirected selection of that response. By contrast, S-R mechanisms cannot explain this effect for two reasons. First, the heroin-seeking response was never reinforced in the withdrawal state, so an S-R association could not form between withdrawal and the response. The other S-R variant is also not viable, because if withdrawal impaired cognition promoting control over heroin-seeking by S-R links between external cues and the response, then withdrawal should have promoted heroin-seeking in rats that had not previously experienced heroin in that state (had no incentive learning experience). However, this effect was not found. Thus, the outcomerevaluation procedure provides a compelling test of whether the impact of negative affective states on drug-seeking behaviour is driven by incentive learning rather than $S-R$ mechanisms.

The current study utilised a human outcome-revaluation procedure to test whether acute depressed mood statements would prime goal-directed alcohol-seeking to a greater extent in individuals who report drinking to cope with negative affect. One hundred and twenty-eight alcohol drinkers first completed questionnaires of alcohol use disorder, drinking to cope with negative affect and depression symptoms. Participants then learned at baseline that two responses earned alcohol and food points respectively in a set of two alternative forced choice trials. At test, participants rated the valence of 
randomly sampled negative affective statements (e.g. 'I don't think things are ever going to get better') and positive statements (e.g. 'I feel enthusiastic and confident now'), and following each statement, chose between the alcohol- and food-seeking responses in extinction (i.e. no alcohol or food points were earned). It was expected that negative mood statements would increase the percentage of alcohol- versus food-seeking choices compared to positive statements and baseline to a greater extent in individuals who report drinking to cope with negative affect. This finding would support a merger of motivational negative reinforcement theory (Cox and Klinger 1988; Kassel et al. 2003; Khantzian 1997; Marlatt 1996; Mathew et al. 2017; Sinha 2001) and incentive learning theory (Dickinson et al. 2002; Hogarth 2012; Hogarth and Chase 2011; Hutcheson et al. 2001). That is, the finding would suggest that explicit beliefs concerning the greater reward value of alcohol in the negative affective state are the causal mechanism driving the intentional choice to drink, rather than an automatic S-R mechanism. This theoretical distinction has important implications for alcohol treatment strategy, suggesting that for drinkers who report negative coping motives, the most effective treatment should be forms of cognitive behaviour therapy (CBT) that directly target negative coping motives (Anker et al. 2016; Bradizza et al. 2017; Kushner et al. 2013; Stasiewicz et al. 2013), whereas mood management (Monti et al. 1990; Monti and Rohsenow 1999; Pettinati et al. 2013), and attempts to counter-train implicit learning processes (Gladwin et al. 2015) are likely to be comparatively less effective in this group.

\section{Method}

\section{Participants}

The study recruited 128 drinkers (50\% male) who reported drinking alcohol at least monthly. The study was approved by the University of Exeter Psychology Ethics Committee.

\section{Questionnaires}

Questionnaires were the alcohol use disorders inventory test (AUDIT: Babor et al. 2001) and the Reasons for Drinking Questionnaire (RFDQ: Zywiak et al. 1996) from which the negative coping subscale was examined. This subscale includes seven items which ask participants to assess how important different reasons for drinking are for them, including sadness, anger, frustration, anxiety, tension, illness, and relationship difficulties, measured on a $0-10$ scale ranging from 'not at all important' to 'very important'. Depression symptoms were recorded using Beck's Depression Inventory II (Beck et al. 1996).

\section{Mood induction effect on alcohol choice}

Baseline alcohol versus food choice (see Fig. 1): participants were presented with two $275-\mathrm{ml}$ bottles of Beck's beer and two 45-g Cadbury's Dairy Milk chocolate bars on the desk and instructed: 'In this task, you can earn points for beer and chocolate to take with you at the end. In each trial, choose the UP or DOWN arrow key to earn these rewards. Your points

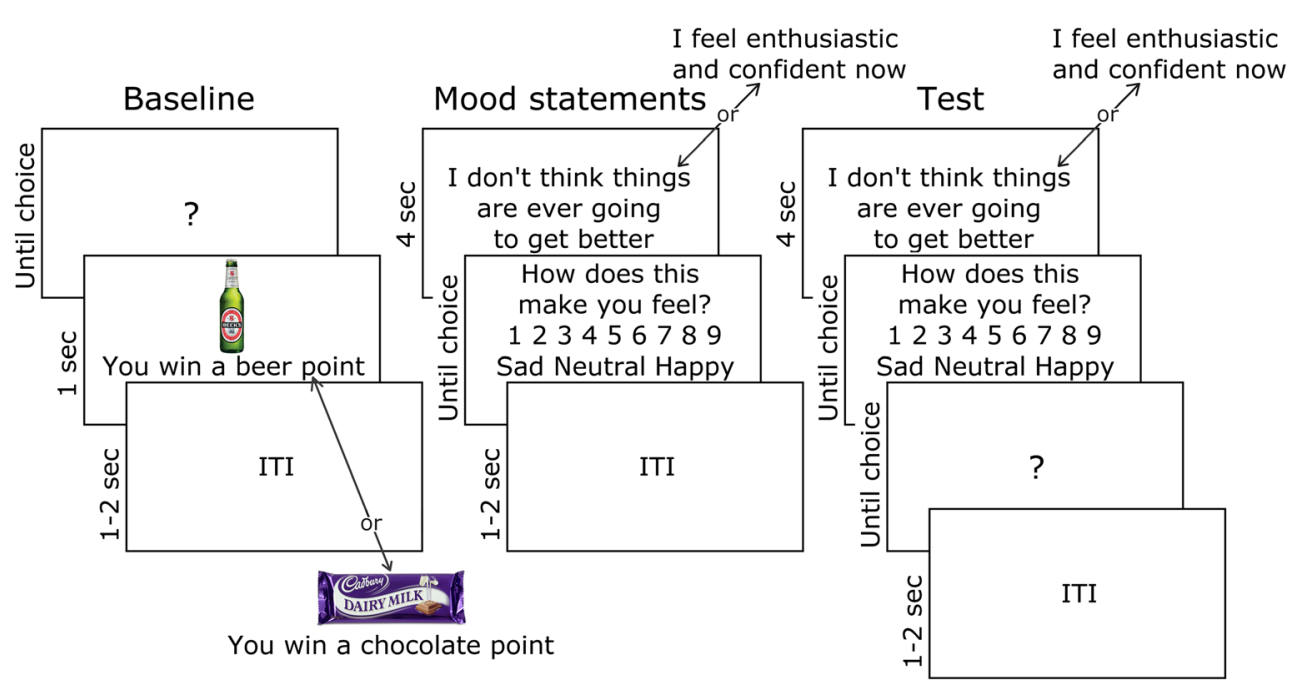

Fig. 1 Outcome-revaluation procedure used to test the impact of negative and positive mood statements on goal-directed alcoholseeking. At baseline, participants learned that left and right keyboard responses earned beer and chocolate points, respectively. Participants then rated how sad or happy randomly sampled negative and positive mood statements made them feel (see Table 1 for a list of statements). At test, participants continued to rate the valence of negative and positive statements, but after each statement, made a free choice between the beer- or chocolate-seeking response trained at baseline, but without feedback of whether beer or chocolate points were earned (i.e. in extinction). Negative mood statements were expected to increase the percentage of beer- over chocolate-seeking responses, compared to positive statements and baseline, in individuals who reported drinking to cope with negative affect. This would demonstrate greater sensitivity to the motivational effect of negative mood statements on goal-directed alcohol-seeking 
will be drawn from a lottery at the end of the experiment. You may win the 2 beers, the 2 chocolate bars, all 4 or none at all. The more points you earn for each reward, the better your chances of winning more of that reward'. This was a deception - all participants received a small Freddo chocolate bar at the end of the experiment. Trials began with a question mark, whereupon an up or down key press produced the alcohol or chocolate outcome, comprising an image of the reinforcer plus corresponding text 'You win a [beer/chocolate] point' for $1 \mathrm{~s}$. The response-outcome contingencies were counterbalanced between subjects. After 32 baseline trials, contingency knowledge was tested with two questions in random order: 'Which arrow key earned [beer/chocolate] the UP or DOWN key?'

Mood statements: participants were instructed to carefully consider negative and positive mood statements listed in Table 1 (Hogarth et al. 2015; Velten 1968; Westermann et al. 1996). In each trial, either a negative or positive statement was presented for $4 \mathrm{~s}$, before participants rated how sad to happy this made them feel on a 9-point scale. Across eight trials, the presented statement was randomly selected from the set of 32 , comprising 16 negative and 16 positive statements (see Table 1).

Test: participants were instructed: 'In this part of the task, please continue to consider the mood statements. Also, the UP and DOWN arrow keys will win beer and chocolate points in the same way as earlier in the task. You will be told how many points you have earned at the end. Press the space bar to begin'. In each test, a mood statement was presented for $4 \mathrm{~s}$, before participants rated how sad-happy it made them feel. Upon presentation of the question mark, the alcohol- or food-seeking response was made. No outcomes were presented at the test stage, so any effect of mood statements on choice must be mediated by goal-directed knowledge of the response-outcome contingencies acquired in training. Across 64 test trials, there were two cycles of 32, each containing 16 negative and 16 positive statements selected in random order. Retention of contingency knowledge over the test phase was tested as before.

\section{Analytical plan}

Percent alcohol- versus food-seeking choice was calculated from baseline trials and test trials with negative and positive statements $(>50 \%=$ preference for alcohol, $<50 \%=$ preference for food). An ANOVA first tested the difference between these three conditions. Separate general linear models (GLMs) were conducted with percent alcohol choice as the dependent variable, condition (3) as the within-subjects variable and a single, continuous between-subjects variable in each model: AUDIT, negative coping motives (RFDQ), and depression symptoms (BDI). A significant interaction indicated that the difference in alcohol choice between conditions varied with the continuous variable. A main effect of the continuous variable indicated that there was a simple correlation between overall alcohol choice and the continuous variable. Interactions were followed up by GLMs contrasting the three conditions.
Table 1 Negative and positive mood statements used in the study. At the beginning of each test trial, one statement was presented (randomly sampled from the entire set of 32), and rated for how sad-happy it makes the participant feel, before a choice was made between the alcohol- or food-seeking response in extinction

\begin{tabular}{|c|c|}
\hline Negative mood statements & Positive mood statements \\
\hline - I feel a little down today & - I feel cheerful and lively \\
\hline - My work is harder than I expected & $\begin{array}{l}\text { - On the whole, I have very little difficulty in } \\
\text { thinking clearly }\end{array}$ \\
\hline - Sometimes I feel so guilty that I can't sleep & - I'm pleased that most people are so friendly to me \\
\hline $\begin{array}{l}\text { - I wish I could be myself, but nobody likes me when I } \\
\text { am }\end{array}$ & - I can make friends extremely easily \\
\hline $\begin{array}{l}\text { - Today is one of those days when everything I do is } \\
\text { wrong }\end{array}$ & - I feel enthusiastic and confident now \\
\hline - I doubt that I'll ever make a contribution in the world & - There should be a lot of good times coming along \\
\hline $\begin{array}{l}\text { - I feel like my life is in a rut that I'm never going to get } \\
\text { out }\end{array}$ & - I'm able to do things accurately and efficiently \\
\hline • My mistakes haunt me, I've made too many & - I know that I can achieve the goals I set \\
\hline - Life is such a heavy burden & - I have a sense of power and vigour \\
\hline - I'm tired of trying & - I'm feeling amazingly good today \\
\hline $\begin{array}{l}\text { - Even when I give my best effort, it just doesn't seem to } \\
\text { be good enough }\end{array}$ & - I feel highly perceptive and refreshed \\
\hline - I don't think things are ever going to get better & - I can concentrate hard on anything I do \\
\hline - I feel worthless & - My thinking is clear and rapid \\
\hline - What's the point of trying & $\begin{array}{l}\text { - Life is so much fun; it seems to offer so many } \\
\text { sources of fulfilment }\end{array}$ \\
\hline - I feel cheated by life & - Life is firmly in my control \\
\hline $\begin{array}{l}\text { - Every time I turn around, something else has gone } \\
\text { wrong }\end{array}$ & - I'm really feeling sharp now \\
\hline
\end{tabular}




\section{Results}

\section{Participants}

Of the 128 participants recruited, five failed to accurately report the response-outcome contingencies after baseline or test and so were excluded, as is standard in this paradigm (e.g. Hogarth et al. 2015). The mean characteristics of the 123 participants who were analysed were as follows: age $=20.9$ $(\mathrm{SD}=1.7$, range $=18-32)$, AUDIT $=10.2(5.1,1-25)$, RFDQ negative coping score $=1.7(1.5,0-5.9)$, and $\mathrm{BDI}=5.7(5.4$, $0-26)$. There were 61 males and 62 females.

\section{Experimental task}

Negative and positive statements were rated as having significantly different valence. The negative mood statements were rated as making participants feel sad $(M=2.71, S E M=0.09)$, whereas the positive statements were rated as making participants feel happy $(M=7.36, S E M=0.09), F(1122)=1036.42$, $p<.001, \eta_{\mathrm{p}}{ }^{2}=.895$. There was no overall difference in alcohol choice measured between the baseline, test-negative, and test-positive conditions, $F(1122)=1.14, p=.32, \eta_{\mathrm{p}}{ }^{2}=.009$, as shown in Fig. 1a.

Table 2 shows the correlation matrix between the questionnaire scales, baseline alcohol versus food choice, and the mood-induced increase in alcohol choice (the difference between test-negative and test-positive conditions). The GLM with AUDIT shown in Fig. 2b showed a significant main effect of AUDIT, $F(1121)=9.52, p=.003, \eta_{\mathrm{p}}{ }^{2}=.073$ but no interaction between AUDIT and condition, $F(2242)=0.14$, $p=.87, \eta_{\mathrm{p}}{ }^{2}=.001$. By contrast, the GLM with RFDQ negative coping shown in Fig. $2 \mathrm{c}$ revealed a significant main effect of RFDQ negative coping, $F(1121)=8.93, p=.003$, $\eta_{\mathrm{p}}{ }^{2}=.069$, and significant interaction between RFDQ negative coping and condition, $F(2242)=5.54, p=.004$, $\eta_{\mathrm{p}}{ }^{2}=.044$. Specific contrasts indicated that this interaction between RFDQ negative coping and condition was significant when the GLM included baseline and test-negative conditions, $F(1121)=7.33, p=.008, \eta_{\mathrm{p}}^{2}=.057$, and when it included test-negative and test-positive conditions, $F(1121)=7.44, p<.007, \eta_{\mathrm{p}}{ }^{2}=.058$, but not when it included baseline and test-positive conditions, $F(1121)=0.82, p=.37$, $\eta_{\mathrm{p}}{ }^{2}=.007$. Finally, the GLM with BDI shown in Fig. $2 \mathrm{~d}$ revealed a main effect of BDI, $F(1121)=6.50, p=.01$, $\eta_{\mathrm{p}}{ }^{2}=.051$, but no interaction with between BDI and condition, $F(2242)=0.55, p=.58, \eta_{\mathrm{p}}^{2}=.005$. In summary, these results indicate AUDIT, RFDQ negative coping, and BDI all have a simple correlation with baseline and overall alcohol choice, but only RFDQ negative coping is associated with greater sensitivity to the motivational impact of negative mood statements on alcohol-seeking at test.

Secondary analyses were undertaken to explore the role of other variables. A GLM incorporating the second RFDQ subscale, social pressure, and condition (baseline, test-negative, test-positive) revealed no main effect of subscale, $F(1121)=3.62, p=.06, \eta_{\mathrm{p}}{ }^{2}=.029$, or interaction, $F(2242)=2.68, p=.07, \eta_{\mathrm{p}}^{2}=.022$. Similarly, a GLM incorporating the remaining RFDQ subscale, cued craving, and condition (3) revealed a significant main effect of subscale, $F(1121)=7.93, p=.006, \eta_{\mathrm{p}}{ }^{2}=.062$, but no interaction, $F(2242)=.42, p=.66, \eta_{\mathrm{p}}{ }^{2}=.003$. Importantly, the interaction between RFDQ negative coping and condition (3) remained significant when the other two RFDQ subscales were both included (controlled) in the GLM, $F(2238)=6.83, p=.001$, $\eta_{\mathrm{p}}{ }^{2}=.054$. Similarly, the interaction between RFDQ negative coping and condition (3) remained significant when BDI and AUDIT were both included (controlled) in the model, $F(2238)$ $=6.39, p=.002, \eta_{\mathrm{p}}{ }^{2}=.051$. Turning to the gender variable, an ANOVA incorporating gender (2) and condition (3) indicated that males chose more alcohol overall $(\mathrm{M}=34.8, \mathrm{SEM}=3.3)$ than females $(\mathrm{M}=24.8, \mathrm{SEM}=3.3), F(1121)=4.58, p=.03$,

Table 2 Correlation matrix between questionnaire and alcohol-seeking measures

\begin{tabular}{|c|c|c|c|c|}
\hline & \multicolumn{4}{|c|}{ Experiment 1} \\
\hline & BDI & RFDQ negative coping & Baseline alcohol choice & Mood induced alcohol choice \\
\hline AUDIT & $\begin{array}{l}r=.25 \\
p=.005\end{array}$ & $\begin{array}{l}r=.43 \\
p<.001\end{array}$ & $\begin{array}{l}r=.24 \\
p=.007\end{array}$ & $\begin{array}{l}r=-.00 \\
p=.967\end{array}$ \\
\hline BDI & & $\begin{array}{l}r=.43 \\
p<.001\end{array}$ & $\begin{array}{l}r=.19 \\
p=.038\end{array}$ & $\begin{array}{l}r=.05 \\
p=.553\end{array}$ \\
\hline RFDQ negative coping & & & $\begin{array}{l}r=.22 \\
p=.015\end{array}$ & $\begin{array}{l}r=.24 \\
p=.007\end{array}$ \\
\hline Baseline alcohol choice & & & & $\begin{array}{l}r=.07 \\
p=.461\end{array}$ \\
\hline
\end{tabular}

Baseline alcohol choice was the percent choice of alcohol over food at baseline. Mood-induced alcohol choice was the difference in percent alcohol choice between the test-negative and test-positive conditions

$A U D I T$ alcohol use disorders inventory, $R F D Q$ reasons for drinking questionnaire, $B D I$ Beck's Depression Inventory 
$\eta_{\mathrm{p}}^{2}=.037$, but there was no interaction between gender and condition, $F(2242)=.75, p=.47, \eta_{\mathrm{p}}^{2}=.006$. A GLM incorporating age and condition (3) revealed no effect of age, $F(1121)=2.33, p=.13, \eta_{\mathrm{p}}^{2}=.019$, or interaction, $F(2242)=.19, p=.83, \eta_{\mathrm{p}}{ }^{2}=.002$. A GLM incorporating the difference in valence rating between negative and positive statements and condition (3) revealed no effect of valence rating, $F(1121)=.37, p=.54, \eta_{\mathrm{p}}^{2}=.003$, or interaction, $F(2242)=1.13, p=.32, \eta_{\mathrm{p}}{ }^{2}=.009$. These results indicate that the relationship between RFDQ negative coping and greater sensitivity to mood-induced alcohol-seeking cannot be explained by other variables measured in the study.

\section{Discussion}

The main finding of the current study was that individuals who reported drinking to cope with negative affect were more sensitive to the motivational impact of negative mood statements promoting goal-directed alcohol- versus food-seeking in an outcome-revaluation procedure. This finding advances previous studies which have also found that coping motives predict sensitivity to mood or stress-induced alcohol-seeking, as indexed by craving, consumption, preferential choice, or cognitive bias (Austin and Smith 2008; Birch et al. 2004; Brady et al. 2006; Cooney et al. 1997; Field and Powell 2007; Field and Quigley 2009; Grant et al. 2007; Rousseau et al. 2011; Woud et al. 2015; Zack et al. 2003) and disconfirms two null results (Field and Powell 2007; Thomas et al. 2014). The novel contribution of the current study was to demonstrate that mood-induced alcohol-seeking can be driven by incentive learning rather than S-R habit processes. Previous studies could not distinguish these accounts. According to the incentive learning account, individuals who reported negative coping motives have learned that alcohol is more rewarding in negative affect states, enabling negative statements to raise the expected value of alcohol, which is integrated with instrumental knowledge of which response
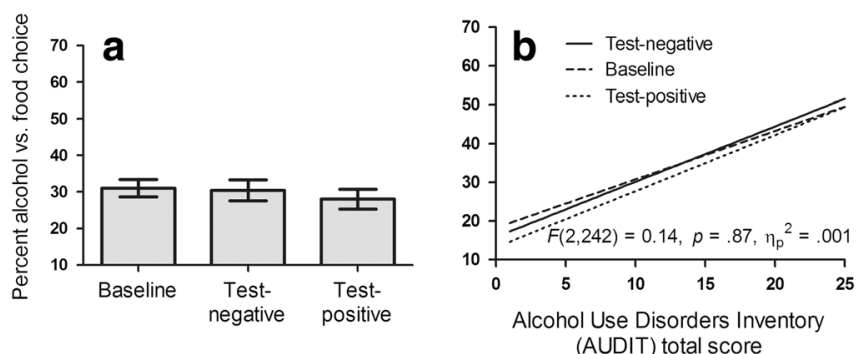

Fig. 2 a Average percent choice of the alcohol- over food-seeking response in baseline, test-negative, and test-positive trials. b-d Regression slopes relating the percent choice of alcohol- over foodseeking responses in baseline, test-negative, and test-positive trials with three continuous between-subjects variables: $\mathbf{b}$ alcohol use disorder AUDIT scores, $\mathbf{c}$ the Reasons for Drinking Questionnaire negative coping subscale, and d Beck's Depression Inventory. The statistical produces alcohol, promoting goal-directed choice of that response. This finding supports a merger of motivational negative reinforcement theories (Cox and Klinger 1988; Kassel et al. 2003; Khantzian 1997; Marlatt 1996; Mathew et al. 2017; Sinha 2001) and incentive learning theory (Dickinson et al. 2002; Hogarth 2012; Hogarth and Chase 2011; Hutcheson et al. 2001), in which explicit beliefs concerning the greater reward value of alcohol in the negative affective state are the causal mechanism driving the intentional choice to drink, rather than an automatic S-R mechanism, in individuals who report negative drinking coping motives.

The putative causal role played by negative coping motives and accompanying sensitivity to mood-induced alcohol-seeking in alcohol dependence and relapse has been supported by a range of studies. In longitudinal studies, self-reported coping motives are a prospective marker for subsequent alcohol dependence (Beseler et al. 2008; Crum et al. 2013a; Crum et al. 2013b; Lazareck et al. 2012; Menary et al. 2011; Merrill et al. 2014; Robinson et al. 2011; Windle and Windle 2015). For instance, Crum et al. (2013b) found that, for individuals who reported drinking to cope with negative affect at baseline, there was a 3.1 times increase in risk of new-onset alcohol dependence and a 3.4 times increased risk of persistent alcohol dependence at follow-up. Second, in cross-sectional studies, a wide range of psychiatric symptoms are associated with more severe alcohol dependence, and this relationship is consistently mediated by self-reported drinking to cope with negative affect, suggesting coping motives are the proximal driver of alcohol dependence (Asberg and Renk 2012; Dvorak et al. 2014; Fossos et al. 2011; Gonzalez et al. 2011; Grayson and Nolen-Hoeksema 2005; Holahan et al. 2001; Kaysen et al. 2007; McDevitt-Murphy et al. 2015; Mooney et al. 2008; O'Hare and Sherrer 2011; Øverup et al. 2015; Peirce et al. 1994; Reardon et al. 2002; Schuck and Widom 2001; Schuckit et al. 2006; Simpson et al. 2014; Stewart et al. 2001; Topper et al. 2011; Ullman et al. 2005; Yeater et al. 2010; Young-Wolff et al. 2009). Third, retrospective interview studies have found that alcoholics typically attribute more
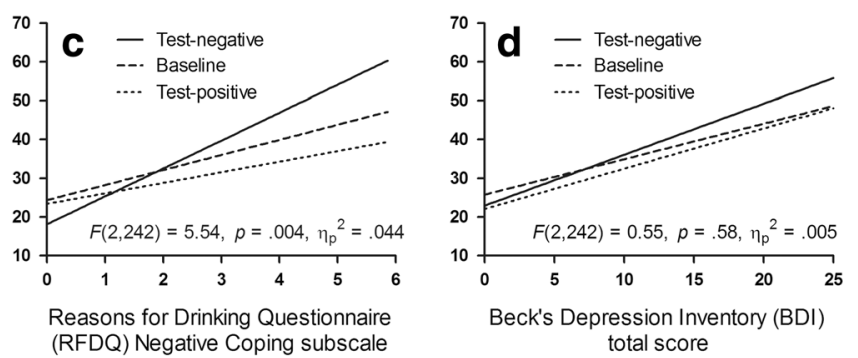

insets report the interaction between the within-subjects variable condition (3) and the continuous between-subjects variable AUDIT, RFDQ, or BDI. The significant interaction involving RFDQ negative coping (c) indicates that individuals who reported drinking to cope with negative affect were more sensitive to the motivational impact of negative mood statements on goal-directed alcohol-seeking 
than $50 \%$ of relapse episodes to negative affect, interpersonal conflict, or physical ailments, suggesting that reactivity to negative triggers drives relapse (Brown et al. 1990; Hodgins et al. 1995; Hore 1971; Marlatt 1996). Finally, greater increases in alcohol craving following experimental negative mood induction predicts vulnerability to alcohol relapse even when other relevant predictors are controlled (Brady et al. 2006; Cooney et al. 1997; Higley et al. 2011; Sinha et al. 2011) also for cocaine relapse, see (Back et al. 2010; Sinha et al. 2006). For example, Sinha et al. (2011) found that only $0.02 \%$ of high stress-induced craving responders remained abstinent from alcohol at an 80-day follow-up, whereas 35\% of low stress-induced craving responders survived. These studies are consistent with the claim that explicit beliefs that alcohol has a greater reward value in a negative affect state (incentive learning) plays a causal role in driving alcoholseeking behaviour.

By contrast, the main finding cannot be explained by S-R accounts of how depressed mood promotes alcohol-seeking (Baker et al. 2004; Everitt and Robbins 2016; Koob and Volkow 2010; Schwabe et al. 2011). Negative mood statements could not have formed a stronger S-R association with the alcohol- versus food-seeking response, because testing was conducted in extinction and, therefore, neither response was reinforced in the presence of negative mood statements. Similarly, external contextual cues were commonly present when both responses were made during baseline training, and so would have formed equivalent S-R links with the alcohol- and food-seeking responses. Consequently, negative statements could not have promoted alcohol-seeking through either a stronger S-R link to that response, or by facilitating S$\mathrm{R}$ links between external cues and the alcohol-seeking response. Finally, S-R theory could only explain the correlation between coping motives and mood-induced alcohol-seeking by suggesting that coping motives are epiphenomenal rather than causal, which contradicts substantial data demonstrating the importance of coping motives in alcohol dependence noted above.

There are implications for treatment strategy in the concluding that negative mood-induced alcohol-seeking in those who drink to cope is driven by incentive learning rather than more automatic S-R mechanisms. First, if the belief that alcohol has a higher value in negative affect states plays a causal role in driving alcohol-seeking in individuals who drink to cope, then CBT which targets coping motives should be most effective in this group. Support for this claim comes from the finding that versions of CBT that target negative coping motives are more effective than treatment as usual (Bradizza et al. 2017; Chaney et al. 1978; Jones et al. 1982; Kushner et al. 2013; Monti et al. 1990; Stasiewicz et al. 2013; Watt et al. 2006), and this therapeutic effect is greater in individuals who report negative coping motives (Anker et al. 2016). Second, brief interventions which target coping motives have also produced promising therapeutic outcomes. For example, Conrod et al. (2013) selected high-risk adolescents who were high in anxiety, hopelessness, impulsivity, or sensationseeking and trained them to identify individualised drinking triggers and adaptive coping strategies. This intervention reduced the odds of drinking during the trial by $29 \%$ compared to no treatment, suggesting that targeting coping motives in high-risk individuals may function as an effective preventative strategy. Similarly, Blevins and Stephens (2016) found that in undergraduates drinkers, a single session focusing on negative drinking coping motives and alternative coping strategies (in contrast to normative alcohol education) reduced self-reported drinking problems at a 2-month follow-up, which was mediated by reductions in drinking coping motives (see also Banes et al. 2014). Finally, trait adaptive coping skills have been shown to protect drinkers who reported drinking to cope, from stress-induced priming of alcohol consumption (Merrill and Thomas 2013), and to be associated with reduced negative coping motives and alcohol use problems (Bravo et al. 2016; Fernandez et al. 2010; Littlefield et al. 2010; Murphy and Mackillop 2012; Pearson et al. 2015; Roos et al. 2015; Tull et al. 2015). The implication of these studies is that CBT which targets negative coping motives is potentially the optimal treatment strategy for individuals who drink to cope with negative affect, consistent with the incentive learning account. By contrast, mood management (Monti et al. 1990; Monti and Rohsenow 1999; Pettinati et al. 2013) and attempts to countertrain implicit learning processes (Gladwin et al. 2015) should be comparatively less effective, because they do not tackle the beliefs that drive alcohol-seeking this group.

One important issue for the incentive learning account is whether the motivational impact of adverse states on goaldirected drug-seeking is powerful enough to override the catastrophic costs of drug use and intentions to quit- the hallmark of dependence. Two studies suggest that this is possible. First, Hutcheson et al. (2001) showed that heroin withdrawal could promote goal-directed heroin-seeking. Given that alcohol withdrawal constitutes severe and diverse symptoms, including seizures, delirium tremens, anxiety, depression, and sleep disturbance (Heilig et al. 2010), it is plausible that these states (or anticipation of them) would exert a sufficiently powerful motivating effect on goaldirected alcohol-seeking to override costs and intentions to quit. Second, we recently demonstrated using a similar outcome-revaluation procedure to that in the present study, that negative mood induction increased goal-directed tobacco-seeking even in smokers who were tobacco sated, and who would otherwise reduce their tobacco-seeking when mood induction was absent (Hogarth et al. 2015). The implication is that negative mood acted as a powerful motivational state which was capable of fully overriding satiety, and might therefore plausibly be able to override expected harms and intentions to quit. 
Mood-induced alcohol-seeking did not vary with either AUDIT or BDI scores, despite these scores correlating with RFDQ negative coping (these correlations have also been reported in other studies: Armeli et al. 2010; Bolton et al. 2009; Bravo et al. 2016; Cooper et al. 1995; Gonzalez et al. 2009, 2011; Grant et al. 2009; Holahan et al. 2004; Peirce et al. 1994; Rafnsson et al. 2006; Turner et al. 1997). Furthermore, the relationship between mood-induced alcohol-seeking and RFDQ negative coping remained significant when AUDIT and BDI scores were controlled, consistent with the view that coping motives are the proximal determinant of the mood induction effect (Cooper et al. 1995; Hufford et al. 2003; Marlatt 1985; Shiffman 2005; Witkiewitz et al. 2007; Zack et al. 1999). In contrast, some studies have found that sensitivity to mood-induced alcohol-seeking increased with alcohol dependence and depression symptoms. Specifically, three studies found that mood-induced alcoholseeking was greater in more dependent drinkers (Sinha et al. 2009; Zack et al. 2003; Zack et al. 2006), but several others have either reported nonsignificant associations (Austin and Smith 2008; Cooney et al. 1997; Field and Powell 2007; Field and Quigley 2009; Woud et al. 2015; Zack et al. 1999) or have not reported the analysis despite having the relevant data (Birch et al. 2004; Grant et al. 2007; McGrath et al. 2016; Owens et al. 2014; Potthast et al. 2015; Rousseau et al. 2011). With respect to depression symptoms, two studies have shown that the correlation between depression symptoms and alcohol craving was numerically greater in a negative mood than a neutral induction condition, providing weak evidence that depression is associated with greater sensitivity to moodinduced alcohol-seeking (Cooney et al. 1997; Owens et al. 2014). More compellingly, we recently demonstrated that negative mood-induced tobacco-seeking was greater in smokers with current major depressive disorder than those without (Hogarth et al. 2017), corroborating an earlier smoking study reporting a similar effect across subclinical depression symptoms (Fucito and Juliano 2009). In the current study, the failure to find that mood-induced alcohol-seeking was associated with AUDIT and BDI scores was presumably due to the student sample containing too few individual at the more severe end of these spectrums.

To conclude, this study found that individuals who reported drinking to cope with negative affect were more sensitive to the motivational impact of depressive statements on goaldirected alcohol-seeking behaviour in an outcomerevaluation procedure. This effect can be explained by incentive learning, where the negative mood state raises the expected value of alcohol promoting goal-directed alcohol-seeking, but not by S-R habit theory. We have drawn upon wider literature to argue that the development of alcohol dependence, vulnerability to relapse, and the persistence of alcohol use despite substantial costs and intention to quit may be better explained by excessive affective incentive learning than by propensity to habitual or automatic control over alcoholseeking behaviour.

Acknowledgements The work was supported by the ESRC and Alcohol Research UK.

Open Access This article is distributed under the terms of the Creative Commons Attribution 4.0 International License (http:// creativecommons.org/licenses/by/4.0/), which permits unrestricted use, distribution, and reproduction in any medium, provided you give appropriate credit to the original author(s) and the source, provide a link to the Creative Commons license, and indicate if changes were made.

\section{References}

Anker JJ, Kushner MG, Thuras P, Menk J, Unruh AS (2016) Drinking to cope with negative emotions moderates alcohol use disorder treatment response in patients with co-occurring anxiety disorder. Drug Alcohol Depend 159:93-100

Armeli S, Conner TS, Cullum J, Tennen H (2010) A longitudinal analysis of drinking motives moderating the negative affect-drinking association among college students. Psychol Addict Behav 24:38-47

Asberg K, Renk K (2012) Substance use coping as a mediator of the relationship between trauma symptoms and substance use consequences among incarcerated females with childhood sexual abuse histories. Subst Use Misuse 47:799-808

Austin JL, Smith JE (2008) Drinking for negative reinforcement: the semantic priming of alcohol concepts. Addict Behav 33:1572-1580

Babor TF, Higgins-Biddle JC, Saunders JB, Monteiro MG (2001) AUDIT: the alcohol use disorders identification test guidelines for use in primary care. 2nd edn. Volume

Back SE, Hartwell K, DeSantis SM, Saladin M, McRae-Clark AL, Price KL, Moran-Santa Maria MM, Baker NL, Spratt E, Kreek MJ, Brady KT (2010) Reactivity to laboratory stress provocation predicts relapse to cocaine. Drug Alcohol Depend 106:21-27

Baker TB, Piper ME, McCarthy DE, Majeskie MR, Fiore MC (2004) Addiction motivation reformulated: an affective processing model of negative reinforcement. Psychol Rev 111:33-51

Banes KE, Stephens RS, Blevins CE, Walker DD, Roffman RA (2014) Changing motives for use: outcomes from a cognitive-behavioral intervention for marijuana-dependent adults. Drug Alcohol Depend 139:41-46

Beck AT, Steer RA, Ball R, Ranieri WF (1996) Comparison of Beck Depression Inventories-IA and-II in psychiatric outpatients. J Person Assess 67:588-597

Beseler CL, Aharonovich E, Keyes KM, Hasin DS (2008) Adult transition from at-risk drinking to alcohol dependence: the relationship of family history and drinking motives. Alcohol Clin Exp Res 32:607-616

Birch CD, Stewart SH, Wall A, McKee SA, Eisnor SJ, Theakston JA (2004) Mood-induced increases in alcohol expectancy strength in internally motivated drinkers. Psychol Addict Behav 18:231-238

Blevins CE, Stephens RS (2016) The impact of motives-related feedback on drinking to cope among college students. Addict Behav 58:68-73

Bolton JM, Robinson J, Sareen J (2009) Self-medication of mood disorders with alcohol and drugs in the National Epidemiologic Survey on Alcohol and Related Conditions. J Affect Disord 115:367-375

Bradizza CM, Stasiewicz PR, Zhuo Y, Ruszczyk M, Maisto SA, Lucke JF, Brandon TH, Eiden RD, Slosman KS, Giarratano P (2017) Smoking cessation for pregnant smokers: development and pilot test of an emotion regulation treatment supplement to standard smoking cessation for negative affect smokers. Nicotine Tob Res 19:578-584 
Brady KT, Back SE, Waldrop AE, McRae AL, Anton RF, Upadhyaya HP, Saladin ME, Randall PK (2006) Cold pressor task reactivity: predictors of alcohol use among alcohol-dependent individuals with and without comorbid posttraumatic stress disorder. Alcohol Clin Exp Res 30:938-946

Bravo AJ, Pearson MR, Stevens LE, Henson JM (2016) Depressive symptoms and alcohol-related problems among college students: a moderated-mediated model of mindfulness and drinking to cope. $\mathrm{J}$ Stud Alcohol Drugs 77:661-666

Brown SA, Vik PW, McQuaid JR, Patterson TL, Irwin MR, Grant I (1990) Severity of psychosocial stress and outcome of alcoholism treatment. J Abnorm Psychol 99:344-348

Chaney EF, O'Leary MR, Marlatt GA (1978) Skill training with alcoholics. J Consult Clin Psychol 46:1092-1104

Conrod PJ, O'Leary-Barrett M, Newton N, Topper L, Castellanos-Ryan N, Mackie C, Girard A (2013) Effectiveness of a selective, personality-targeted prevention program for adolescent alcohol use and misuse: a cluster randomized controlled trial. JAMA Psychiatry 70:334-342

Cooney NL, Litt MD, Morse PA, Bauer LO, Gaupp L (1997) Alcohol cue reactivity, negative-mood reactivity, and relapse in treated alcoholic men. J Abnorm Psychol 106:243-250

Cooper ML, Frone MR, Russell M, Mudar P (1995) Drinking to regulate positive and negative emotions: a motivational model of alcohol use. J Pers Soc Psychol 69:990-1005

Corbit LH, Nie H, Janak PH (2012) Habitual alcohol seeking: time course and the contribution of subregions of the dorsal striatum. Biol Psychiatry 72:389-395

Cox WM, Klinger E (1988) A motivational model of alcohol use. J Abnorm Psychol 97:168-180

Crum RM, La Flair L, Storr CL, Green KM, Stuart EA, Alvanzo AAH, Lazareck S, Bolton JM, Robinson J, Sareen J, Mojtabai R (2013a) Reports of drinking to self-medicate anxiety symptoms: longitudinal assessment for subgroups of individuals with alcohol dependence. Depress Anxiety 30:174-183

Crum RM, Mojtabai R, Lazareck S et al (2013b) A prospective assessment of reports of drinking to self-medicate mood symptoms with the incidence and persistence of alcohol dependence. JAMA Psychiatry 70:718-726

Dickinson A, Balleine BW (2010) The cognitive/motivational interface. In: Kringelbach ML, Berridge KC (eds) Pleasures of the brain the neural basis of taste, smell and other rewards. Oxford University Press, Oxford, pp 74-84

Dickinson A, Wood N, Smith JW (2002) Alcohol seeking by rats: action or habit? Q J Exp Psychol B 55:331-348

Dvorak RD, Pearson MR, Day AM (2014) Ecological momentary assessment of acute alcohol use disorder symptoms: associations with mood, motives, and use on planned drinking days. Exp Clin Psychopharmacol 22:285-297

Eissenberg T (2004) Measuring the emergence of tobacco dependence: the contribution of negative reinforcement models. Addiction 99:5-29

Everitt BJ, Robbins TW (2016) Drug addiction: updating actions to habits to compulsions ten years on. Annu Rev Psychol 67:23-50

Fernandez AC, Wood MD, Stein LA, Rossi JS (2010) Measuring mindfulness and examining its relationship with alcohol use and negative consequences. Psychol Addict Behav 24:608-616

Field M, Powell H (2007) Stress increases attentional bias for alcohol cues in social drinkers who drink to cope. Alcohol Alcohol 42: 560-566

Field M, Quigley M (2009) Mild stress increases attentional bias in social drinkers who drink to cope: a replication and extension. Exp Clin Psychopharmacol 17:312-319

Fossos N, Kaysen D, Neighbors C, Lindgren KP, Hove MC (2011) Coping motives as a mediator of the relationship between sexual coercion and problem drinking in college students. Addict Behav 36:1001-1007
Fucito LM, Juliano LM (2009) Depression moderates smoking behavior in response to a sad mood induction. Psychol Addict Behav 23:546-551

Gladwin TE, Rinck M, Eberl C, Becker ES, Lindenmeyer J, Wiers RW (2015) Mediation of cognitive bias modification for alcohol addiction via stimulus-specific alcohol avoidance association. Alcohol Clin Exp Res 39:101-107

Gonzalez VM, Bradizza CM, Collins RL (2009) Drinking to cope as a statistical mediator in the relationship between suicidal ideation and alcohol outcomes among underage college drinkers. Psychol Addict Behav 23:443-451

Gonzalez VM, Reynolds B, Skewes MC (2011) Role of impulsivity in the relationship between depression and alcohol problems among emerging adult college drinkers. Exp Clin Psychopharmacol 19: 303-313

Grant VV, Stewart SH, Birch CD (2007) Impact of positive and anxious mood on implicit alcohol-related cognitions in internally motivated undergraduate drinkers. Addict Behav 32:2226-2237

Grant VV, Stewart SH, Mohr CD (2009) Coping-anxiety and copingdepression motives predict different daily mood-drinking relationships. Psychol Addict Behav 23:226-237

Grayson CE, Nolen-Hoeksema S (2005) Motives to drink as mediators between childhood sexual assault and alcohol problems in adult women. J Traum Stress 18:137-145

Hall FS, Der-Avakian A, Gould TJ, Markou A, Shoaib M, Young JW (2015) Negative affective states and cognitive impairments in nicotine dependence. Neurosci Biobehav Rev 58:168-185

Hardy L, Mitchell C, Seabrooke T, Hogarth L (2017) Drug cue reactivity involves hierarchical instrumental learning: evidence from a biconditional Pavlovian to instrumental transfer task. Psychopharmacology

Heilig M, Egli M, Crabbe JC, Becker HC (2010) Acute withdrawal, protracted abstinence and negative affect in alcoholism: are they linked? Addict Biol 15:169-184

Higley A, Crane N, Spadoni A, Quello S, Goodell V, Mason B (2011) Craving in response to stress induction in a human laboratory paradigm predicts treatment outcome in alcohol-dependent individuals. Psychopharmacology 218:121-129

Hodgins DC, el-Guebaly N, Armstrong S (1995) Prospective and retrospective reports of mood states before relapse to substance use. J Consult Clin Psychol 63:400-407

Hogarth L (2012) Goal-directed and transfer-cue-elicited drug-seeking are dissociated by pharmacotherapy: evidence for independent additive controllers. J Exp Psychol Anim Behav Process 38:266-278

Hogarth L, Chase HW (2011) Parallel goal-directed and habitual control of human drug-seeking: implications for dependence vulnerability. J Exp Psychol Anim Behav Process 37:261-276

Hogarth L, Field M, Rose AK (2013) Phasic transition from goal-directed to habitual control over drug-seeking produced by conflicting reinforcer expectancy. Addict Biol 18:88-97

Hogarth L, He Z, Chase HW, Wills AJ, Troisi J II, Leventhal AM, Mathew AR, Hitsman B (2015) Negative mood reverses devaluation of goal-directed drug-seeking favouring an incentive learning account of drug dependence. Psychopharmacology 232:3235-3247

Hogarth L, Mathew AR, Hitsman B (2017) Current major depression is associated with greater sensitivity to the motivational effect of both negative mood induction and abstinence on tobacco-seeking behavior. Drug Alcohol Depend 176:1-6

Holahan CJ, Moos RH, Holahan CK, Cronkite RC, Randall PK (2001) Drinking to cope, emotional distress and alcohol use and abuse: a ten-year model. J Stud Alcohol 62:190-198

Holahan CJ, Moos RH, Holahan CK, Cronkite RC, Randall PK (2004) Unipolar depression, life context vulnerabilities, and drinking to cope. J Consult Clin Psychol 72:269-275

Hore BD (1971) Life events and alcoholic relapse. Br J Addict 66:83-88 
Hufford MR, Witkiewitz K, Shields AL, Kodya S, Caruso JC (2003) Relapse as a nonlinear dynamic system: application to patients with alcohol use disorders. J Abnorm Psychol 112:219-227

Hutcheson DM, Everitt BJ, Robbins TW, Dickinson A (2001) The role of withdrawal in heroin addiction: enhances reward or promotes avoidance? Nat Neurosci 4:943-947

Jones SL, Kanfer R, Lanyon RI (1982) Skill training with alcoholics: a clinical extension. Addict Behav 7:285-290

Kassel JD, Stroud LR, Paronis CA (2003) Smoking, stress, and negative affect: correlation, causation, and context across stages of smoking. Psychol Bull 129:270-304

Kaysen D, Dillworth TM, Simpson T, Waldrop A, Larimer ME, Resick PA (2007) Domestic violence and alcohol use: trauma-related symptoms and motives for drinking. Addict Behav 32:1272-1283

Khantzian EJ (1997) The self-medication hypothesis of substance use disorders: a reconsideration and recent applications. Harv Rev Psychiatry 4:231-244

Koob GF, Volkow ND (2010) Neurocircuitry of addiction. Neuropsychopharmacology 35:1051-1051

Kushner MG, Maurer EW, Thuras P, Donahue C, Frye B, Menary KR, Hobbs J, Haeny AM, Van Demark J (2013) Hybrid cognitive behavioral therapy versus relaxation training for co-occurring anxiety and alcohol disorder: a randomized clinical trial. J Consult Clin Psychol 81:429-442

Lazareck S, Robinson JA, Crum RM, Mojtabai R, Sareen J, Bolton JM (2012) A longitudinal investigation of the role of self-medication in the development of comorbid mood and drug use disorders: findings from the National Epidemiologic Survey on Alcohol and Related Conditions (NESARC). J Clin Psychiatry 73:e588-e593

Littlefield AK, Sher KJ, Wood PK (2010) Do changes in drinking motives mediate the relation between personality change and "maturing out" of problem drinking? J Abnorm Psychol 119:93-105

Marlatt GA (1985) Cognitive factors in the relapse process. In: MG A, GJ R (eds) Relapse prevention. Guilford Press, New York, pp 128-200

Marlatt GA (1996) Taxonomy of high-risk situations for alcohol relapse: evolution and development of a cognitive-behavioral model. Addiction 91:37-49

Mathew AR, Hogarth L, Leventhal AM, Cook JW, Hitsman B (2017) Cigarette smoking and depression comorbidity: systematic review and proposed theoretical model. Addiction 112:401-412

McDevitt-Murphy ME, Fields JA, Monahan CJ, Bracken KL (2015) Drinking motives among heavy-drinking veterans with and without posttraumatic stress disorder. Addict Res Theory 23:148-155

McGrath E, Jones A, Field M (2016) Acute stress increases ad-libitum alcohol consumption in heavy drinkers, but not through impaired inhibitory control. Psychopharmacology in press

Menary KR, Kushner MG, Maurer E, Thuras P (2011) The prevalence and clinical implications of self-medication among individuals with anxiety disorders. J Anxiety Disord 25:335-339

Merrill JE, Thomas SE (2013) Interactions between adaptive coping and drinking to cope in predicting naturalistic drinking and drinking following a lab-based psychosocial stressor. Addict Behav 38: $1672-1678$

Merrill JE, Wardell JD, Read JP (2014) Drinking motives in the prospective prediction of unique alcohol-related consequences in college students. J Stud Alcohol Drugs 75:93-102

Miles FJ, Everitt BJ, Dickinson A (2003) Oral cocaine seeking by rats: action or habit? Behav Neurosci 117:927-938

Monti PM, Abrams DB, Binkoff JA, Zwick WR, Liepman MR, Nirenberg TD, Rohsenow DJ (1990) Communication skills training, communication skills training with family and cognitive behavioral mood management training for alcoholics. J Stud Alcohol 51:263-270

Monti PM, Rohsenow DJ (1999) Coping-skills training and cue-exposure therapy in the treatment of alcoholism. Alcohol Res Health 23:107-115

Mooney JL, Minor KI, Wells JB, Leukefeld C, Oser CB, Staton Tindall M (2008) The relationship of stress, impulsivity, and beliefs to drug use severity in a sample of women prison inmates. Int J Offender Ther Comp Criminol 52:686-697

Murphy C, Mackillop J (2012) Living in the here and now: interrelationships between impulsivity, mindfulness, and alcohol misuse. Psychopharmacology 219:527-536

O'Hare T, Sherrer M (2011) Drinking motives as mediators between PTSD symptom severity and alcohol consumption in persons with severe mental illnesses. Addict Behav 36:465-469

Øverup CS, DiBello AM, Brunson JA, Acitelli LK, Neighbors C (2015) Drowning the pain: intimate partner violence and drinking to cope prospectively predict problem drinking. Addict Behav 41:152-161

Owens MM, Ray LA, MacKillop J (2014) Behavioral economic analysis of stress effects on acute motivation for alcohol. J Exp Anal Behav 103:77-86

Pearson MR, Brown DB, Bravo AJ, Witkiewitz K (2015) Staying in the moment and finding purpose: the associations of trait mindfulness, decentering, and purpose in life with depressive symptoms, anxiety symptoms, and alcohol-related problems. Mindfulness 6:645-653

Peirce RS, Frone MR, Russell M, Cooper ML (1994) Relationship of financial strain and psychosocial resources to alcohol use and abuse: the mediating role of negative affect and drinking motives. J Health Soc Behav 35:291-308

Pettinati HM, O'Brien CP, Dundon WD (2013) Current status of cooccurring mood and substance use disorders: a new therapeutic target. Am J Psychiatry 170:23-30

Potthast N, Neuner F, Catani C (2015) When abuse primes addictionautomatic activation of alcohol concepts by child maltreatment related cues in emotionally abused alcoholics. Addict Behav 48:62-70

Rafnsson FD, Jonsson FH, Windle M (2006) Coping strategies, stressful life events, problem behaviors, and depressed affect. Anxiety Stress Coping 19:241-257

Reardon ML, Lang AR, Patrick CJ (2002) An evaluation of relations among antisocial behavior, psychopathic traits, and alcohol problems in incarcerated men. Alcohol Clin Exp Res 26:1188-1197

Robinson J, Sareen J, Cox BJ, Bolton JM (2011) Role of self-medication in the development of comorbid anxiety and substance use disorders: a longitudinal investigation. Arch Gen Psychiatry 68:800-807

Roos CR, Pearson MR, Brown DB (2015) Drinking motives mediate the negative associations between mindfulness facets and alcohol outcomes among college students. Psychol Addict Behav 29:176-183

Rousseau GS, Irons JG, Correia CJ (2011) The reinforcing value of alcohol in a drinking to cope paradigm. Drug Alcohol Depend 118:1-4

Schuck AM, Widom CS (2001) Childhood victimization and alcohol symptoms in females: causal inferences and hypothesized mediators. Child Abuse Neglect 25:1069-1092

Schuckit MA, Smith TL, Chacko Y (2006) Evaluation of a depressionrelated model of alcohol problems in 430 probands from the San Diego prospective study. Drug Alcohol Depend 82:194-203

Schwabe L, Dickinson A, Wolf OT (2011) Stress, habits and drug addiction: a psychoneuroendocrinological perspective. Exp Clin Psychopharmacol 19:53-63

Shiffman S (2005) Dynamic influences on smoking relapse process. J Pers 73:1715-1748

Simpson TL, Stappenbeck CA, Luterek JA, Lehavot K, Kaysen DL (2014) Drinking motives moderate daily relationships between PTSD symptoms and alcohol use. J Abnorm Psychol 123:237-247

Sinha R (2001) How does stress increase risk of drug abuse and relapse? Psychopharmacology 158:343-359

Sinha R, Fox HC, Hong K, Hansen J, Tuit K, Kreek M (2011) Effects of adrenal sensitivity, stress- and cue-induced craving, and anxiety on subsequent alcohol relapse and treatment outcomes. Arch Gen Psychiatry 68:942-952

Sinha R, Fox HC, Hong KA, Bergquist K, Bhagwagar Z, Siedlarz KM (2009) Enhanced negative emotion and alcohol craving, and altered physiological responses following stress and cue exposure in alcohol dependent individuals. Neuropsychopharmacology 34:1198-1208 
Sinha R, Garcia M, Paliwal P, Kreek M, Rounsaville BJ (2006) Stressinduced cocaine craving and hypothalamic-pituitary-adrenal responses are predictive of cocaine relapse outcomes. Arch Gen Psychiatry 63:324-331

Solomon RL, Corbit JD (1973) An opponent-process theory of motivation: II. Cigarette Addict J Abnorm Psychol 81:158-171

Stasiewicz PR, Bradizza CM, Schlauch RC, Coffey SF, Gulliver SB, Gudleski GD, Bole CW (2013) Affect regulation training (ART) for alcohol use disorders: development of a novel intervention for negative affect drinkers. J Subst Abus Treat 45:433-443

Stewart SH, Zvolensky MJ, Eifert GH (2001) Negative-reinforcement drinking motives mediate the relation between anxiety sensitivity and increased drinking behavior. Pers Individ Differ 31:157-171

Thomas SE, Merrill JE, von Hofe J, Magid V (2014) Coping motives for drinking affect stress reactivity but not alcohol consumption in a clinical laboratory setting. J Stud Alcohol Drugs 75:115-123

Topper LR, Castellanos-Ryan N, Mackie C, Conrod PJ (2011) Adolescent bullying victimisation and alcohol-related problem behaviour mediated by coping drinking motives over a 12 month period. Addict Behav 36:6-13

Tull MT, Bardeen JR, DiLillo D, Messman-Moore T, Gratz KL (2015) A prospective investigation of emotion dysregulation as a moderator of the relation between posttraumatic stress symptoms and substance use severity. J Anxiety Disord 29:52-60

Turner NE, Annis HM, Sklar SM (1997) Measurement of antecedents to drug and alcohol use: psychometric properties of the inventory of drug-taking situations (IDTS). Behav Res Ther 35:465-483

Ullman SE, Filipas HH, Townsend SM, Starzynski LL (2005) Trauma exposure, posttraumatic stress disorder and problem drinking in sexual assault survivors. J Stud Alcohol 66:610-619

Velten E (1968) A laboratory task for induction of mood states. Behav Res Ther 6:473-482

Watt M, Stewart S, Birch C, Bernier D (2006) Brief CBT for high anxiety sensitivity decreases drinking problems, relief alcohol outcome expectancies, and conformity drinking motives: evidence from a randomized controlled trial. J Ment Health 15:683-695
Westermann R, Spies K, Stahl G, Hesse FW (1996) Relative effectiveness and validity of mood induction procedures: a meta-analysis. Eur J Soc Psychol 26:557-580

Wikler A (1984) Conditioning factors in opiate addiction and relapse. J Subst Abus Treat 1:279-285

Windle M, Windle RC (2015) A prospective study of stressful events, coping motives for drinking, and alcohol use among middle-aged adults. J Stud Alcohol Drugs 76:465-473

Witkiewitz K, van der Maas HLJ, Hufford MR, Marlatt GA (2007) Nonnormality and divergence in posttreatment alcohol use: reexamining the project MATCH data "another way.". J Abnorm Psychol 116:378-394

Woud ML, Becker ES, Rinck M, Salemink E (2015) The relationship between drinking motives and alcohol-related interpretation biases. J Behav Ther Exp Psychiatry 47:102-110

Yeater EA, Austin JL, Green MJ, Smith JE (2010) Coping mediates the relationship between posttraumatic stress disorder (PTSD) symptoms and alcohol use in homeless, ethnically diverse women: a preliminary study. Psychol Trauma Theory Res Pract Policy 2: 307-310

Young-Wolff KC, Kendler KS, Sintov ND, Prescott CA (2009) Moodrelated drinking motives mediate the familial association between major depression and alcohol dependence. Alcohol Clin Exp Res 33:1476-1486

Zack M, Poulos CX, Fragopoulos F, MacLeod CM (2003) Effects of negative and positive mood phrases on priming of alcohol words in young drinkers with high and low anxiety sensitivity. Exp Clin Psychopharmacol 11:176-185

Zack M, Poulos CX, Fragopoulos F, Woodford TM, MacLeod CM (2006) Negative affect words prime beer consumption in young drinkers. Addict Behav 31:169-173

Zack M, Toneatto T, MacLeod CM (1999) Implicit activation of alcohol concepts by negative affective cues distinguishes between problem drinkers with high and low psychiatric distress. J Abnorm Psychol 108:518-531

Zywiak WH, Connors GJ, Maisto SA, Westerberg VS (1996) Relapse research and the reasons for drinking questionnaire: a factor analysis of Marlatt's relapse taxonomy. Addiction 91:121-130 